\title{
Condição de Saúde Bucal de População de 11 a 15 Anos de Idade em Comunidade
} Quilombola Sitio Veiga

\section{Condition of Popular Health of Population from 11 to 15 Years of Age in Community Quilombola Site Veiga}

Maria Jeysiane de Oliveira e Silva1, Cristiane Sousa da Silva², Cosmo Helder Ferreira da Silva ${ }^{3}$, Sofia Vasconcelos Carneiro ${ }^{4}$

\section{RESUMO}

A cárie é a principal fonte de dor e desordens funcionais e estéticas na boca. Na falta de tratamento, a doença compromete a estrutura dentária, influenciando negativamente na qualidade de vida. O objetivo do trabalho é avaliar as condições de saúde bucal da comunidade quilombola na faixa etária de 11 a 15 anos do Sítio Veiga, no município de Quixadá-CE. Trata-se de um estudo de campo populacional de caráter transversal, descritivo, com abordagem quantitativa. O presente estudo contou com 12 participantes pertencentes à comunidade na faixa etária de 11 a 15 anos de ambos os sexos. A coleta de dados ocorreu na própria comunidade, com aplicação de um questionário, obtendose dados socioeconômicos, culturais, de conhecimento sobre cárie e de condição de saúde bucal. Realizou-se exame clínico através da inspeção oral com auxílio de espátula de madeira descartável, em cadeiras e sob luz natural para avaliação e preenchimento de odontograma. Os resultados obtidos demonstram que, enquanto $21 \%(n=3)$ afirmaram não ter conhecimento sobre o assunto de saúde bucal, a média do índice de CPO-D, o qual avalia dentes cariados, perdidos e obturados, foi de 4,1, sendo classificado como moderado, segundo a Organização Mundial de Saúde. O componente cariado foi o de maior valor do índice. Diante disso, conclui-se que a população estudada possui um índice moderado para doença cárie, necessitando de atividade com foco na prevenção e tratamento desse problema de saúde pública.

Palavras-chave: Cárie. Saúde Bucal. Quilombo Sítio Veiga.

\section{ABSTRACT}

Caries is the main source of pain and functional and aesthetic disorders in the mouth. In the absence of treatment, the disease compromises dental structure, negatively influencing the quality of life. The objective of this study is to evaluate the oral health conditions of the quilombola community in the age group of 11 to 15 years of Sítio Veiga in the municipality of Quixadá-CE. This is a cross-sectional, population-based, descriptive study with a quantitative approach. The present study had 12 participants belonging to the community in the age group of 11 to 15 years of both sexes. The data collection took place in the community itself with the application of a questionnaire obtaining socioeconomic, cultural, knowledge about caries and oral health condition. Clinical examination was performed through oral inspection with the aid of a disposable wooden spatula, in chairs and under natural light for evaluation and filling of odontogram. The results obtained demonstrate that $21 \%(n=3)$ reported not having knowledge about oral health. The mean CPO-D index, where it evaluates decayed, lost and obturated teeth, was 4.1 and classified as moderate according to the World Health Organization. The caries component was the highest value in the index. Therefore, it is concluded that the population studied has a moderate index for caries disease, requiring activity as a focus in the prevention and treatment of this public health problem.
${ }^{1}$ Graduada em Odontologia pelo Centro Universitário Católica de Quixadá - UNICATÓLICA.

E-mail:

jeysianemacario@hotmail.com

${ }^{2}$ Mestre em Educação Brasileira. Universidade Federal do Ceará UFC.

${ }^{3}$ Mestre em Sociobiodiversidade e Tecnologias Sustentáveis UNILAB (2016). Docente do Centro Universitário Católica de Quixadá - UNICATÓLICA.

${ }^{4}$ Mestre em Odontopediatria pela Faculdade de Odontologia São Leopoldo Mandic - Campinas SP. Docente do Centro Universitário Católica de Quixadá - UNICATÓLICA.

Keywords: Caries. Oral Health. Quilombo Sítio Veiga. 


\section{INTRODUÇÄAO}

Em conformidade com a Organização Mundial da Saúde, o aumento ocasional de risco de doenças bucais está referido a aspectos socioculturais que abrangem as condições de vida e o baixo grau de escolaridade. Nesse contexto, a doença cárie ainda é um obstáculo de saúde bucal expressivo entre as populações desfavorecidas financeiramente nos países desenvolvidos e em desenvolvimento (PERES et al., 2005).

A cárie apresenta caráter multifatorial, envolvendo fatores determinantes e predisponentes (SELWITZ; ISMAIL; PITTS, 2007). A lesão cariosa progride de maneira lenta na maior parte dos indivíduos, geralmente não é autolimitante e, na falta de tratamento, a doença pode agravar-se até destruir totalmente a estrutura dentária, causando problemas estéticos e funcionais (FEJERSKOV; KIDD, 2005).

Os fatores causadores dessa enfermidade, além dos microrganismos na superfície dental, são também a higiene incorreta, hábitos alimentares inadequados, colonização bacteriana, composição da saliva, entre outros, que influenciam o metabolismo das bactérias sobre os dentes, modulando a atividade da cárie (LEITES; PINTO; SOUSA, 2006).

A perda dentária é o pior desfecho decorrente da cárie. Teoricamente, a exodontia é considerada consequência do agravo do quadro de doenças bucais, como a cárie. Porém, na prática, o que se percebe é que essa é a saída encarada como a solução definitiva para a dor. Tal solução é motivada principalmente pela falta de acesso a serviços odontológicos (COSTA et al., 2013).

Vargas e Paixão (2005) confrontam essa ideia ao se deparar com uma controvérsia que é o fato de que, se existe a falta de acesso a serviços odontológicos, como existe para a extração, e ao acesso a esse serviço, nota-se que o déficit está na necessidade de um trabalho de prevenção através dos serviços de saúde.

A cárie dentária é a principal fonte de dor e desordens funcionais e estéticas na boca. Mesmo sendo possível preveni-la, ela continua sendo a mais predominante doença bucal, principalmente em crianças (ANTUNES; PERES; MELO, 2006).

Os fatores dietéticos, por sua vez, influenciam os dentes, reagindo com a superfície do esmalte e servindo de substrato para os microrganismos cariogênicos da microbiota oral. Devido a esse fato, uma dieta de baixo teor cariogênico deve ser orientada (CAMPOS; ZUANON; CAMPOS, 2003). Os açúcares naturalmente presentes nos 
alimentos, como a lactose, são menos acidificantes e, por isso, menos cariogênicos (BARROS, 2014).

Marcenes e Bonecker (2000) afirmam que os fatores socioeconômicos devem ser analisados ao estudar a cárie dentária, pois a desigualdade social, como a má distribuição de renda, a falta de participação na riqueza nacional, o desemprego, o analfabetismo e a exclusão social afetam diretamente o aumento da presença dessa doença, por conta da falta de acesso aos serviços odontológicos.

Diante desse cenário, a população quilombola, ao ser excluída do seu direito à saúde, como foi relatado anteriormente, além do difícil acesso a essa comunidade, faz com que essa população se torne mais vulnerável em relação aos serviços odontológicos.

O grande desafio da Odontologia é atuar na educação da população jovem, fornecendo informações necessárias ao desenvolvimento de hábitos para manter a saúde e prevenir doenças bucais, em uma mudança de atitude em relação às doenças bucais, as quais frequentemente são consideradas inevitáveis pela população (VASCONCELOS; SÁ, 2009).

Flores e Drehmer (2003) explicam que as atividades educativas podem ser bem trabalhadas em diversos espaços, como por exemplo em escolas, onde possa permitir a expansão e o fortalecimento da saúde através de um trabalho coletivo e participativo entre toda a comunidade escolar, incluindo família e crianças/jovens, já que a escola representa um ambiente educacional e social propício para trabalhar conhecimentos e mudanças.

Ao estudar a identidade cultural e necessidade de assistência à saúde das comunidades quilombolas, tendo em vista a herança cultural sofrida e as condições de vida que apresentam indivíduos geralmente isolados e com baixo nível de renda, notase a carência de acesso ao serviço odontológico dessas comunidades (CARDOSO, 2010; FREITAS et al., 2011; ROSA, 2012). Diante deste contexto, o objetivo do trabalho é avaliar as condições de saúde bucal da comunidade quilombola na faixa etária de 11 a 15 anos do Sítio Veiga, no município de Quixadá-CE.

\section{MATERIAIS E METODOS}

Trata-se de um estudo de campo populacional de caráter transversal, descritivo, com abordagem quantitativa. A amostra deste estudo foi composta por 12 adolescentes, referente à amostra total da comunidade no período da pesquisa, com idade de 11 a 15 
anos de idade, de ambos os sexos, pertencentes ao Quilombo Sítio Veiga. Os pais ou responsáveis assinaram o Termo de Consentimento Livre e Esclarecido autorizando a participação dos menores nessa pesquisa.

Para coleta de dados, foi aplicado aos pais/responsáveis um questionário semiestruturado contendo informações socioeconômicas e culturais da família, e os adolescentes responderam sobre os hábitos de saúde bucal. Em seguida, foi realizado um levantamento epidemiológico onde cada paciente teve sua própria ficha clínica (odontograma) e, a partir do exame clínico bucal, foi investigada a presença de cárie dentária na dentição permanente através do índice de CPO-D (índice de dentes cariados, perdidos e obturados, segundo a Organização Mundial de Saúde).

Os exames clínicos odontológicos tiveram os critérios de diagnóstico e a metodologia do levantamento por única examinadora calibrada. A calibração foi realizada em aula teórica (4hrs) e prática (4hrs), a fim de haver concordância entre a própria pesquisadora. Os exames foram realizados na própria comunidade sob luz natural, utilizando espátula de madeira para auxílio da visualização dos dentes, além do Equipamento de Proteção Individual Completo (EPIs).

A Comunidade Quilombola Sítio Veiga localiza-se no Sertão Central, na cidade de Quixadá, no estado do Ceará, na Serra do Estevão, Distrito de Dom Maurício. Esta se apresenta por zona rural, estando distante $25 \mathrm{~km}$ da sede de Quixadá e $3 \mathrm{~km}$ de Dom Maurício. $O$ ingresso à comunidade se dá através da subida da serra, e a chegada à localidade transcorre por um difícil caminho, tendo em vista que a pista possui muitas curvas sinuosas e várias partes da estrada são de terra, com diferentes saliências (COSTA, 2015). É uma comunidade certificada pela Fundação Palmares e, conforme os dados levantados pelo Incra, em outubro de 2012 havia 141 quilombolas, distribuídos em 39 famílias cadastradas. Estas moram dentro do território e apenas oito famílias se autodeclararam não quilombolas.

Atualmente, para se chegar ao quilombo, existem duas maneiras: com transporte próprio ou com o transporte coletivo que faz a linha entre Quixadá e Dom Maurício algumas vezes na semana.

A dificuldade de acesso e a falta de incentivo dos órgãos públicos fazem com que o quilombo não conte com muitos equipamentos e infraestrutura. Falta posto de saúde, escolas e saneamento básico. A iluminação é muitas vezes insuficiente, havendo assim muitos pontos escuros que causam sensação de insegurança. $O$ acesso à água é feito através de poços profundos ou cisternas (GRANGEIRO; MAIA; NOGUEIRA, 2017). 
Quanto à educação, segundos dados levantados pelo Incra, há um índice elevado de analfabetismo, sendo $28,5 \%$ do total em idade escolar. A ausência de escolas na região faz com que crianças e jovens tenham que se deslocar de ônibus para a sede do Distrito de Dom Maurício, a cerca de $3 \mathrm{~km}$ da comunidade, por um caminho de terra irregular e quase inacessível em quadra chuvosa. Em visitas à comunidade e conversas com crianças e jovens em idade escolar, e até mesmo relatos dos pais, é possível perceber que a escola que atende os moradores não está preparada para uma formação completa da população, visto que elas já passaram por diversos episódios de preconceitos por causa da cor, cabelo ou costume (GRANGEIRO; MAIA; NOGUEIRA, 2017).

A implantação de cisternas veio com o Projeto Dom Helder Câmara (PDHC), programa governamental ligado ao Ministério de Desenvolvimento Agrário (MDA), com a construção de diversas cisternas de placa nas residências das famílias quilombolas (Relatório Técnico de Identificação e Delimitação/ RTID, Incra, 2012).

O meio de sustento baseia-se na agricultura desde o início da ocupação da Serra do Estevão pelos quilombolas, que arrendavam terras de proprietários vizinhos para fazer roçado (RTID). A produção agrícola é fundamentalmente de subsistência, porém, em épocas propícias à agricultura, quando a produção aumenta, parte dela é vendida.

O presente estudo foi aprovado pelo Comitê de Ética do Centro Universitário Católico de Quixadá com o protocolo de número 1.287.445, atendendo aos termos da Resolução 466/12 do Conselho Nacional de Saúde. Essa pesquisa foi realizada dentro de um projeto de extensão, nomeado de Núcleo Multidisciplinar de Ensinamento Quilombola (Numeq), o qual tem como objetivo a intervenção na comunidade do Sítio Veiga a partir das necessidades dela, associada ao conhecimento das relações étnico-raciais nas mais diversas áreas do conhecimento, entre elas: Educação Física, Farmácia, Odontologia, Enfermagem, Fisioterapia, Direito, Psicologia, Arquitetura e Urbanismo.

Para análise dos dados, foi realizada a análise descritiva, utilizando médias e porcentagens no programa Microsoft Exce ${ }^{\circledR} 2016$.

\section{RESULTADOS}

A presente pesquisa teve como amostra total 12 participantes, sendo $58,4 \%(n=7)$ do sexo feminino e $41,6 \%(n=5)$ do sexo masculino, de uma Comunidade Quilombola no munícipio de Quixadá, no Ceará.

Todos $(n=12)$ da amostra consideram-se de cor negra, vivem com menos de um salário-mínimo, recebem benefício do governo federal, moram em casa própria, com luz 
elétrica e sem água encanada. A principal fonte de informação é através de telejornal; quanto à leitura, a amostra informou que 58,3\% $(n=7)$ não leem nenhum livro, 25\% $(n=3)$ leem de um a dois livros por ano e $16,7 \%(n=2)$ leem de três a cinco livros.

Em relação ao esporte, $83,3 \%(n=10)$ praticam algum esporte, sendo que todos $(n=10)$ afirmaram jogar futebol, e 16,7\% (n=2) não praticam nenhum esporte. Quanto ao índice de insatisfação dos entrevistados em relação à falta de água e à dificuldade de acesso à comunidade, sendo ambos apontados como o principal problema, com um índice de 33\% $(n=12)$ cada, em segundo lugar a saúde foi citada por $31 \%(n=11)$, e o lixo obteve apenas $3 \%(n=1)$ de citação, não sendo considerado problema para aquela comunidade. Já $79 \%$ $(n=9)$ dos participantes relataram ter escutado falar em saúde bucal, enquanto $21 \%(n=3)$ afirmaram não ter conhecimento sobre o assunto (Gráfico 1).

Gráfico 1. Índice de conhecimento sobre o assunto saúde bucal

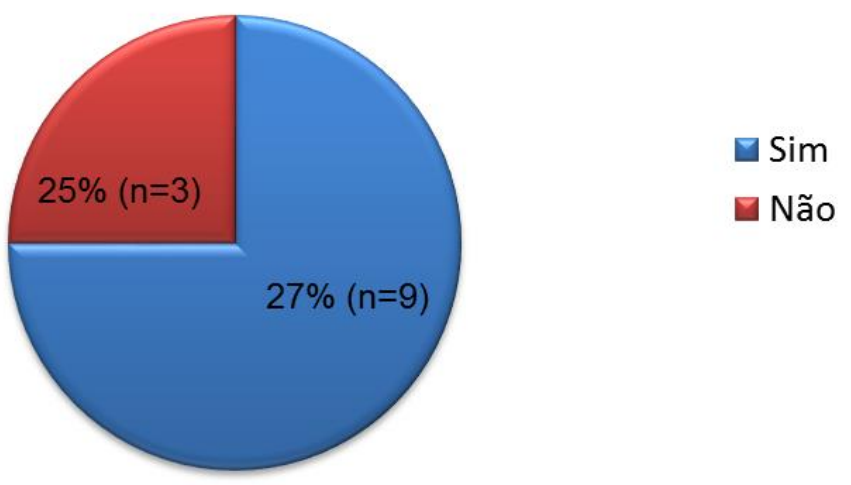

Quando questionados sobre o consumo de açúcar, relacionando a quantidade ou a frequência na ingestão com cárie dentária, dos entrevistados, 42\% ( $n=5)$ afirmaram o item correto, que seria a frequência na ingestão, enquanto $58 \%(n=7)$ relataram que a quantidade era o fator mais prejudicial.

Outro dado relacionado ao conhecimento questionado foi qual o período no qual se deve ter uma maior atenção à escovação dentária: 58,3\% $(n=7)$ da amostra relataram que no período noturno deve ser dada uma maior atenção, enquanto 41,7\% (n=5) afirmaram que o período da manhã deve ser mais enfatizado. O questionário trazia também o período da tarde, não havendo nenhuma citação por esse período pelos entrevistados. $42 \%(n=5)$ afirmaram que a troca deve ocorrer quando as cerdas começam a se abrir, $33 \%(n=4)$ com um mês após o uso da escova dentária e 25\% ( $n=3)$ afirmaram que a troca deve ocorrer a cada três meses.

Durante o estudo, os entrevistados foram questionados sobre as suas percepções de saúde bucal. Foi solicitado que eles se auto avaliassem sobre como estaria essa condição. 
Dos 12 participantes, 67\% ( $n=8)$ consideraram que a sua saúde bucal se encontrava boa, $17 \%(n=2)$ afirmaram que sua condição de saúde bucal poderia ser considerada muito boa e apenas $16 \%(n=2)$ consideram de regular a muito ruim, conforme gráfico 2 .

Gráfico 2. Percepções dos entrevistados sobre a sua saúde bucal

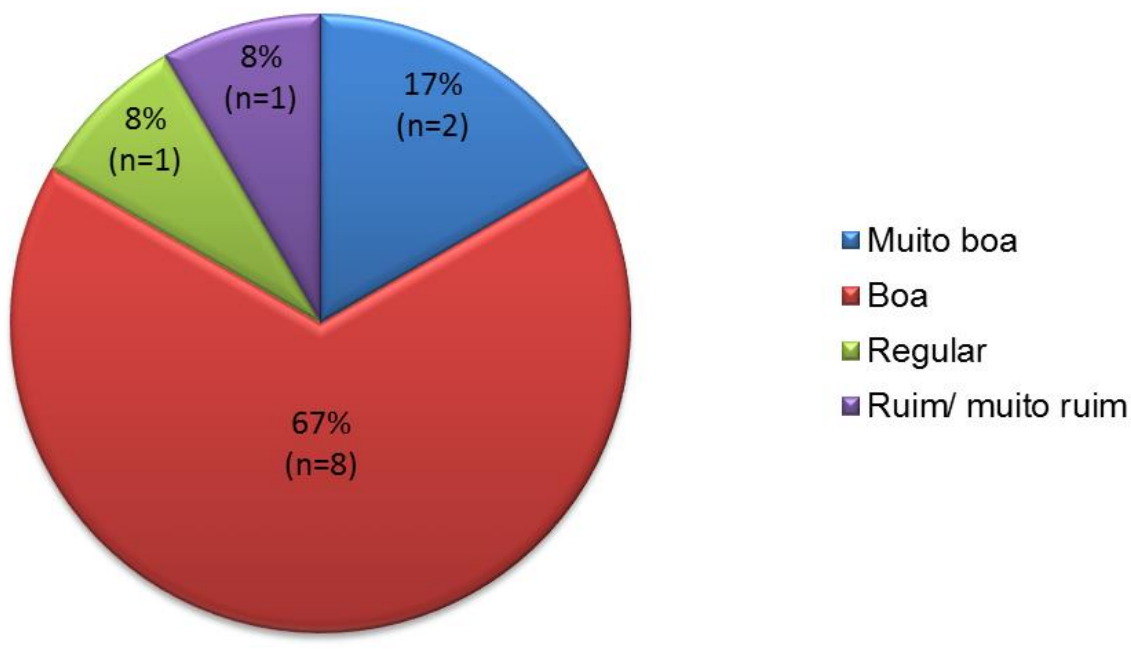

A tabela 1 mostra a quantidade de cada um dos componentes do índice de CPO-D, organizado em valores médios para a idade entre 11 e 15 anos. A média do índice de CPO$\mathrm{D}$ da presente pesquisa foi de 4,1 , enquadrando-se como moderado segundo valores da OMS.

O quadro epidemiológico brasileiro, em relação à saúde bucal, reflete com nitidez alguma das principais características da nossa sociedade. O último SB Brasil - Pesquisa Nacional de Saúde Bucal - foi realizado em 2010 (BRASIL, 2010).

Entre os resultados mais significativos estão os relativos à cárie dentária. Em crianças de 12 anos, idade-índice utilizada internacionalmente para fazer comparações, o índice CPO (somados dentes cariados, perdidos ou obturados) apresentou uma média de 2,1. Em 2003, essa média chegou a 2,8, havendo assim uma redução de $25 \%$ em 7 anos. No componente relativo aos dentes não tratados (cariados), a redução foi de 29\% (1,7 para 1,2). O percentual de crianças "livres de cárie" (CPO = 0) passou de 31\% em 2003 para 44\% em 2010, indicando que, em crianças de 12 anos, ocorreu significativa redução na prevalência e na gravidade da doença, associada a um maior acesso a serviços odontológicos restauradores (BRASIL, 2010). 
Tabela 1. Valores absolutos do índice de CPO-D da Comunidade Quilombola do Sítio Veiga em adolescentes de 11 a 15 anos

\begin{tabular}{ll}
\hline Componentes do CPO-D & $\%$ \\
\hline Cariados & $54 \%(\mathrm{n}=27)$ \\
\hline Perdidos & $20 \%(\mathrm{n}=10)$ \\
\hline Obturados & $26 \%(\mathrm{n}=13)$ \\
\hline Índice de CPO-D & 4,1
\end{tabular}

O gráfico 3 apresenta os principais motivos que levam os entrevistados a procurar o atendimento odontológico: $83 \%(n=10)$ afirmaram que só procuram o serviço quando estão referindo dores de dente e $17 \%(n=2)$ afirmaram que a procura é realizada a cada seis meses para tratamento preventivo.

Gráfico 3. Motivo para a procura do dentista

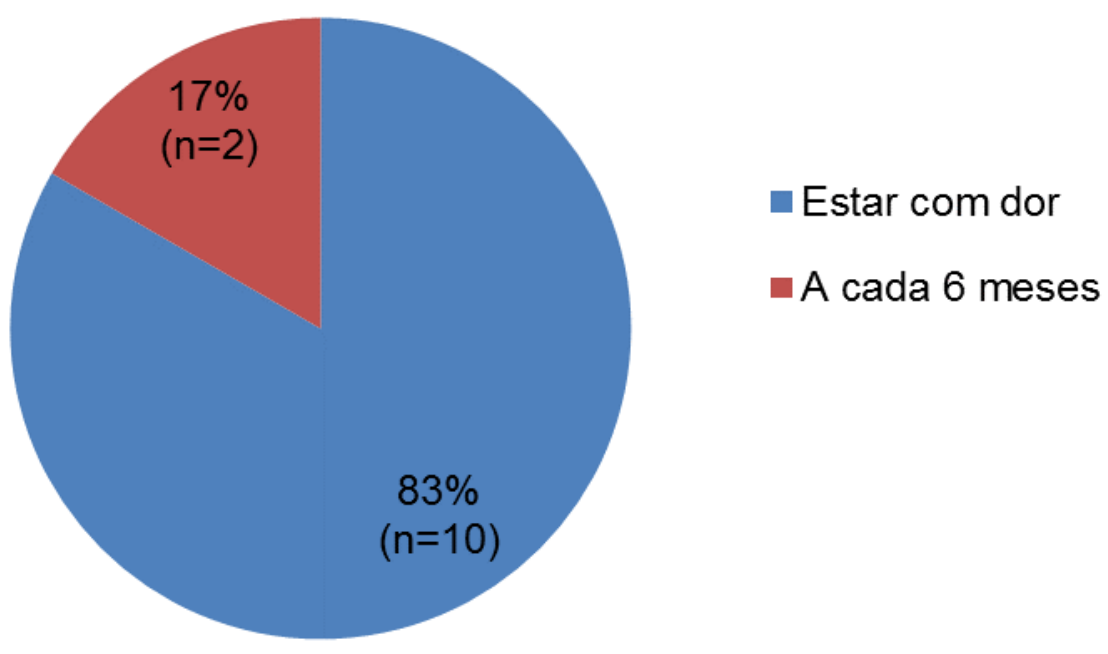

\section{DISCUSSÁO}

A população negra do Brasil consiste no conjunto de pretos e pardos, dada por meio de autodeclaração, que, segundo o Censo de 2010, é aproximadamente $54 \%$ da nossa população. Entretanto, a desigualdade de oportunidades com os brancos faz-se evidente. Dito de outra forma, a dinâmica do racismo é estrutural na nossa sociedade, na qual seus significados reverberam sobre o tratamento dados aos grupos raciais, impondo barreiras de acessos a direitos e negligenciando oportunidades. As disparidades étnico-raciais vêm adquirindo relevância crescente em saúde coletiva e, particularmente, em Odontologia.

Por muitos anos, a ideia de democracia racial foi difundida no país - e ainda é, não permitindo avanços na relação entre saúde e raça, não obstante relacionar saúde bucal e 
raça. Porém, ações que permeiam o movimento negro culminaram na criação da Política Nacional de Saúde Integral da População Negra (PNSIPN), instituída pela Portaria oo 992 de 13 de maio de 2009, onde são definidas diretrizes para esse cuidado no Brasil.

A Política Nacional de Saúde Integral da População Negra define os princípios, a marca, os objetivos, as diretrizes, as estratégias e as responsabilidades de gestão voltados para a melhoria das condições de saúde desse segmento da população. Inclui ações de cuidado, atenção, promoção à saúde e prevenção de doenças, bem como de gestão participativa, participação popular e controle social, produção de conhecimento, formação e educação permanente para trabalhadores de saúde, visando à promoção da equidade em saúde da população negra (BRASIL, 2009).

O Sistema Único de Saúde (SUS), por meio da Política Governamental para a Saúde Bucal, prevê em seus princípios a equidade, que significa ofertar mais a quem mais precisa, ou seja, prestar relacionado a cada um cuidado igualitário, mas respeitando as desigualdades existentes. E, de acordo com Freitas et al. (2011), essa política prioriza implementar ações de saúde bucal junto às comunidades quilombolas, a fim de garantir um atendimento de caráter não mutilador, universal, integral e com equidade. Portanto, é necessário que os serviços de saúde bucal conheçam e considerem as experiências e valores culturais, bem como as diferentes formas de viver de cada comunidade, para que prestem assistência singular à saúde.

Para Sheiham (2001), o aumento da doença cárie esteve associado ao aumento no consumo do açúcar, pois, em todos os países nos quais a prevalência da doença cárie aumentou, houve também o aumento no consumo per capita desse produto. Esse dado tão importante é desconhecido pela amostra estudada, que relatou que a quantidade é a maior causadora da cárie dentária. A mesma autora justifica que a função dos carboidratos da dieta é estimulante do processo de desmineralização e exerce um efeito cariogênico localmente na superfície do dente.

Segundo a Organização Mundial de Saúde, a classificação da escala do índice de CPO-D é: uma prevalência muito baixa quando o CPO-D varia de 0 a 1,1; baixa prevalência quando essa variação é de 1,2 a 2,6; prevalência moderada quando o intervalo é de 2,7 a 4,4; prevalência alta quando varia de 4,5 a 6,5; e muito alta quando o CPO-D é igual ou maior que 6,6.

A média do índice de CPO-D na presente pesquisa foi de 4,1, indicando uma prevalência moderada. $O$ índice moderado de CPO-D parece ter relação com o pouco 
conhecimento sobre os cuidados de saúde bucal, além de um acesso deficitário à saúde, ocasionado pelos longos trechos desiguais e irregulares que dificulta a passagem de veículos, sendo a principal forma de locomoção em algumas áreas o acesso apenas a pé. As casas são afastadas umas das outras, construídas de tijolos, de um modo geral, sem iluminação pública e água encanada, estando localizadas algumas em altos e outras mais abaixo.

Dados da Pesquisa Nacional de Saúde Bucal demonstram que a média encontrada de 4,1 está acima da média nacional brasileira, que é nessa faixa etária de 2,1, e da média do Nordeste, que é de 2,63, ressaltando que, além dos problemas sociais encontrados, a qualidade de saúde bucal dos entrevistados é considerada bem acima da média (BRASIL, 2010).

Uma das dificuldades encontradas na pesquisa em relação à amostra é a dificuldade de acesso ao Quilombo do Sítio Veiga, visto que, para chegar à comunidade, deve-se subir a serra, tendo em vista que a estrada possui muitas curvas sinuosas. Além disso, a estrada de terra com diferentes saliências dificulta mais ainda o acesso, além da falta de sinalização. A dificuldade de amostra se deu devido à faixa etária dos residentes da comunidade quilombola: em sua maioria, estavam em uma faixa etária inferior aos requisitos do estudo, pois possuíam uma dentição mista e abaixo do preconizado. Assim, optou-se por uma avaliação dos participantes em uma faixa etária de 11 a 15 anos para a classificação e que tinham a dentição permanente.

Essa abordagem do curso de Odontologia deu-se principalmente da necessidade de assistência à saúde das comunidades quilombolas, tendo em vista a herança cultural sofrida e as condições de vida, que apresentam indivíduos geralmente isolados e com baixo nível de renda. Nota-se a carência de acesso ao serviço odontológico nessas comunidades (CARDOSO, 2010; FREITAS et al., 2011; ROSA, 2012). E, entendendo que a condição de saúde bucal é, sem dúvida, um dos mais significativos sinais de exclusão social, seja pelos problemas de saúde localizados na boca, seja pelas imensas dificuldades encontradas no acesso aos serviços assistenciais, dentes e gengivas registram o impacto das precárias condições de vida de pessoas em todo o país.

Quando se pensa nas comunidades quilombolas e seu acesso às políticas de saúde, não há como fechar os olhos ao grave problema das crianças. As comunidades, em sua maioria, caracterizam-se pelo forte vínculo com o meio ambiente. As famílias destas comunidades vivem da agricultura de subsistência, sendo a atividade econômica baseada na mão de obra familiar, para assegurar os produtos básicos 
para o consumo. As crianças aprendem a lida na roça desde muito tenra idade. As condições sanitárias destas populações são insuficientes; a maior parte não possui água tratada e nem esgoto sanitário. Outra característica importante dessas comunidades é a ausência de serviços de saúde locais, fazendo com que, ao surgirem doenças, seus habitantes sejam obrigados a percorrer grandes distâncias em busca de ajuda. Todas estas questões acabam por aumentar o baixo índice de indicadores de saúde entre as crianças quilombolas (FREITAS et al., 2011).

A avaliação sobre a autopercepção das condições de saúde bucal, dada pelos próprios indivíduos, é de suma importância para mudanças comportamentais, sobretudo considerando que o comportamento das pessoas é condicionado por suas percepções e pela importância dada a elas (HAIKAL et al.,2011). De acordo com a autoavaliação, a saúde bucal considerada pelos usuários é boa, sendo essa percepção mais à frente analisada após o exame bucal.

\section{CONSIDERAÇOES FINAIS}

Observou-se um índice de CPO-D de 4,1 na comunidade, sendo considerado moderado de acordo com a Organização Mundial de Saúde. O controle de fatores relacionados com o desenvolvimento e progressão da doença cárie, como acesso aos cuidados odontológicos, condição socioeconômica, água fluoretada e hábito dos indivíduos, é de fundamental importância para se obter uma melhor saúde bucal, sendo necessárias medidas preventivas que diminuam esse problema de saúde pública.

\section{REFERENCIAS}

ANTUNES, J. L. F.; JAHN, G. M.; CAMARGO, M. A. Increasing inequalities in the distribution of dental caries in the Brazilian context in Finland. Community Dental Health, v. 22, p. 94-100, 2005.

ANTUNES, J. L. F.; PERES, M. A.; MELO, T. R. C. Determinantes individuais e contextuais da necessidade de tratamento odontológico na dentição decídua no Brasil. Revista Ciência e Saúde Coletiva, v. 11, n. 1, jan./mar. 2006.

ASSOCIAÇÃO AMERICANA DE DENTISTAS. Saiba mais sobre escovas de dentes. Disponível em: http://www.ada.org/en/science-research/ada-seal-of-acceptance/productcategory-information/toothbrushes. Acesso em: 10 nov. 2016.

BALDANI, M. H.; VASCONCELOS; A. G. G.; ANTUNES, J. L. F. Associação do índice CPO-D com indicadores socioeconômicos e de provisão de serviços odontológicos no estado do Paraná, Brasil. Caderno de Saúde Pública, n. 20, p. 143-152, 2004. 
BARROS, O. B.; PERNAMBUCO, R. A.; TOMITA, N. M. Escovas Dentais. Revista da Faculdade de Odontologia, v. 4, n. 1, jan./abr. 2001.

BRASIL. Ministério da Saúde, Secretaria de Atenção à Saúde. Secretaria de Vigilância em Saúde. SB Brasil 2010: Pesquisa Nacional de Saúde Bucal. Brasília: 2012.

CAMPOS, J. A. D. B.; ZUANON, A. C. C.; CAMPOS, A. G. Influência da alimentação e da nutrição na odontogênese e desenvolvimento de lesões de cárie dental. Jornal Brasileiro de Odontopediatria e Odontologia Bebê, v. 6, n. 31, maio/jun. 2003.

CARDOSO, L. F. C. Sobre imagens e quilombos: notas a respeito da construção da percepção acerca das comunidades quilombolas. Revista de Estudo e Pesquisa em Educação, v. 12, n. 1, 2010.

COMISSÃO PRÓ-ÍNDIO DE SÃO PAULO. Comunidades Quilombolas no Brasil. Disponível em: http://www.cpisp.org.br. Acesso em: 4 abr. 2015.

COSTA, S. M.; ABREU, M. H. N. G.; VASCONCELOS, M.; LIMA, R. C. G. S.; VERDI, M.; FERREIRA, E. F. Desigualdade na distribuição de cárie dentária no Brasil: uma abordagem bioética. Revista Ciência e Saúde Coletiva, v. 18, n. 2, fev. 2013.

COSTA, T. C. Q. Mulheres quilombolas e o pertencimento étnico-racial: elementos para uma análise da constituição dos perfis indenitários na comunidade de Quilombo Sítio Veiga em Quixadá-Ceará. Dissertação (Mestrado). Universidade Estadual do Ceará, Fortaleza, 2015. Disponível em: www.uece.br/mass/index.php/arquivos/doc download/186. Acesso em: 12 set. 2016.

FEJERSKOV, O.; KIDD, E. Cárie dentária: a doença e seu tratamento clínico. São Paulo: Santos, 2005.

FLORES, E. M. T.; DREHMER, T. M. Conhecimentos, percepções, comportamentos e representações de saúde e doença bucal dos adolescentes de escolas públicas de dois bairros de Porto Alegre. Revista Ciência e Saúde Coletiva, v. 8, n. 3, 2003.

FREITAS, D. A.; CABALLERO, A. D.; MARQUES, A. S.; HERNANDEZ, C. I. V.; ANTUNES, S. L. N. O. Saúde e comunidades quilombolas: uma revisão da literatura. CEFAC, v. 13, n. 5, p. 937-943, set./out. 2011.

GUIMARÃES, M. M.; MARCOS, B. Perda de dente relacionada a razões clínicas segundo a classe social. CROMG, v. 1, n. 2, p. 54-61, ago./dez. 1995.

HAIKAL, D. S. A.; PAULA, A. M. B.; MARTINS, A. M. E. B. L.; MOREIRA, A. N.; FERREIRA, E. F. Autopercepção da saúde bucal e impacto na qualidade de vida do idoso: uma abordagem quanti-qualitativa. Revista Ciência e Saúde Coletiva, v. 16, n. 7, p. 3317-3329, 2011.

INSTITUTO BRASILEIRO DE GEOGRAFIA E ESTATÍSTICA (IBGE). Censo 2010. Disponível em: http://www.ibge.gov.br/censo2010/. Acesso em: 15 mar. 2018.

INSTITUTO NACIONAL DE COLONIZAÇÃO E REFORMA AGRÁRIA (INCRA). Estrutura Fundiária: Quilombola. Disponível em: http://www.incra.gov.br/quilombolas. Acesso em: 3 abr. 2015. 
LEITES, A. C. B. R.; PINTO, M. B.; SOUSA, E. R. Aspectos Microbiológicos da Cárie Dental. Salusvita, Bauru, v. 25, n. 2, 2006.

MARCENES, W.; BONECKER, M. J. S. Aspectos epidemiológicos e sociais das doenças bucais. Promoção de Saúde Bucal na Clínica Odontológica. São Paulo: Artes Médicas, 2000.

MINISTÉRIO DA SAÚDE. Portaria № 1.444 de 28 de dezembro de 2000. Diário Oficial da União, Brasília, 29 dez. 2000. Disponível em:

http://www.camara.gov.br/sileg/integras/142359.pdf. Acesso em: 3 abr. 2015.

NOVAIS, S. M. A.; BATALHA, R. P.; GRINFELD, S.; FORTES, T. M.; PEREIRA, M. A. S. Relação doença cárie-açúcar: prevalência em crianças Pesquisa Brasileira de Odontopediatria Clínica Integral, v. 4, n. 3, p. 199-203, set./dez. 2004.

PERES, M. A.; LATORRE, M. R.; SHEIHAM, A. et al. Social and biological early life influences on severity of dental caries in children aged 6 years. Community Dentistry and Oral Epidemiology, v. 33, n. 1, p. 53-63, 2005.

PORTAL DA IGUALDADE. Programa Brasil Quilombola. Disponível em: http://www.portaldaigualdade.gov.br/. Acesso em: 2 abr. 2015.

ROSA, J. A. A. Epidemiologia da saúde bucal da comunidade quilombola Patioba Sergipe/Brasil. Programa de Pós-Graduação em Saúde e Ambiente. Universidade Tiradentes, Aracaju, 2012.

SELWITZ, R. H.; ISMAIL, A. I.; PITTS, N. B. Dental caries. Lancet, n. 369, p. 51-59, 2007. SHEIHAM, A. Strategies for promoting oral health care. Revista Brasileira de Saúde Coletiva, v. 2, n. 1, p. 7-24, 2001.

VARGAS, A. M. D.; PAIXÃO, H. H. Perda dentária e seu significado na qualidade de vida de adultos usuários de serviço público de saúde bucal do Centro de Boa Vista, em Belo Horizonte. Revista Ciência e Saúde Coletiva, v. 10, n. 4, 2005.

VASCONCELOS, M. M. V. B.; SÁ, L. O. A importância da educação em saúde bucal nas Escolas de Ensino Fundamental: Revisão de Literatura. Odontologia Clínica Científica, v. 8, n. 4, out./dez. 2009. 